\title{
Ontology Development For Supporting The Decision On Selecting An Individual Educational Trajectory
}

\author{
Alexandra A. Zakharova \\ Yurga Institute of Technology, TPU Affiliate \\ Yurga, Russia \\ aaz@tpu.ru
}

\author{
Anastasia N. Lazareva \\ Yurga Institute of Technology, TPU Affiliate \\ Yurga, Russia \\ lazarevanastya@mail.ru
}

\begin{abstract}
The paper deals with selecting a lifetime educational trajectory by an individual. The ontological approach is proposed for description of a subject domain. A special emphasis is put on modeling the relations between subjects influencing the selection of forms and academic programs by an individual.
\end{abstract}

Keywords—individual, ontology, relations, class.

\section{INTRODUCTION}

One of the important challenges the present day economy has to take is assuring compliance of a personnel occupational skill structure with available and forecasting needs of businesses and organizations in the country. Professional knowledge unable to satisfy current industrial manufacturing demands hardly furthers the efficient use of equipment and labor recourses, makes it difficult to introduce new technologies, and create innovative products. Advancement of a personnel occupational skill structure via lifelong professional training is thought to be an outstanding possibility to improve manufacturing efficiency.

The necessity to obtain knowledge, skills and abilities required for successful professional life makes an individual choose a corresponding academic program [1]. Here there are a great number of educational opportunities: a person might get education first and be employed afterwards; an individual might pass all the educational levels or complete only one of them; he or she might be involved into profession, starting his/her training simultaneously through getting part-time education or doing various further education courses etc.

This problem is of particular importance especially for the young, who have just started their professional career. One can't forget their choice is often interconnected with their family (parents) or employees, since yesterday's schoolchildren can hardly have an idea about their future professional career, identify its advantages and disadvantages. Therefore, their decisions only partially agree with their own aims.

Both consumers of educational services and employees directly receive educational process outcomes. Quality of education can be assessed differently by employers and educational institutions.

Educational institutions evaluate quality of education as a compliance degree of content and competences of graduates with federal state educational standards (ФГОС). As a consequence, state accreditation of educational institutions and academic programs aims exclusively at control of graduate's knowledge; its criteria are not interrelated with demands of employees and labor market and provide no assessment of graduate's preparedness for professional activities. It is noteworthy, that a lot has been done recently to involve employees and educational institutions into cooperation.

Employees and students assess training in a way different from that of educational institutions, since they evaluate quality of education as consumers. If training furthers a successful competition on the labor market and making a professional career, a graduate thinks it is of high quality. When an employee hires a graduate it is not the compliance with the requirements of federal state educational standards that is in the focus, but a professional competence, an ability to orientate oneself in the manufacturing process, solve unconventional problems, make independent decisions within own responsibilities and be responsible for them.

Despite different aims of government authorities and administration, employees, educational institutions and individuals in assessing educational trajectories, all of them influence decisions of each other. When choosing an academic program individuals and educational institutions pay special attention to the demand for graduates majoring in a particular field on the labor market. Employees prefer graduates from acknowledged educational institutions. The ambition of universities is that their students can start a professional career immediately after completion of an academic program.

Therefore, it is necessary to develop an IT environment and methods to support making a decision on the selection of an individual educational trajectory, which provide all interested subjects with tools for assessment of academic programs. In this study an educational trajectory is thought as an individual lifetime sequence of educational activity forms. It is to say that this problem is weakly structured and formalized; decisions are made in conditions of high uncertainty in the decision-making environment and insufficient information for analysis.

Some aspects of this problem have been discussed by scientists from different countries so far. For instance, quality of education vs. labor market conditions analysis [2], assessment of curriculum quality $[3,4]$, selection of further academic programs relying on students' evaluation of their professional competence levels and own preferences [5]; development of criteria for 
academic program assessment [6], creation of an appropriate trajectory when doing particular courses (including computerassisted ones) [7] etc.

However, the problem of consecutively changing forms of lifetime educational activity and development of methods to support making decisions on the selection of an educational trajectory with regard to opinions of all interested subjects have not received any comprehensible consideration yet [8], therefore, modeling the interrelations between objects in the explored subject domain is an urgent scientific problem.

\section{SELECTION OF THE MODEL FOR DESCRIPTION OF A SUBJECT DOMAIN}

A lot of models for knowledge presentation are available at present. The models given below are the most acknowledged ones:

- Productional models are based on rules, they make it possible to present knowledge in form of sentences like: "If condition, action". The disadvantage of a productional model is in mutual contradiction of productions if a lot of them are accumulated;

- Network models (or semantic networks) refer to graphs in knowledge engineering which represent the sense of data on the whole. Nodes of a graph mark concepts and objects, and arcs refer to relations between objects. Its shortcoming is in insufficient presentation of a subject domain structure, it is also difficult to make a conclusion;

- A frame model uses a notion of a frame. A frame is a structure of data to represent a conceptual object. The principal drawback of frame models is a lacking mechanism to control the conclusion.

Ontology is an attempt to carry out comprehensive and detailed formalization of a particular knowledge field with the help of a conceptual scheme. Intellectual systems applying ontologies as data bases can be easily modified if necessary.

When ontology projecting and developing the following aims are set:

- imitating modeling of processes with the purpose of their improvement;

- fast logical conclusions with regard to a significant amount of information in order to support decision making;

- assuring availability for users' apprehending great amounts of multi-structured information, knowledge exchange between people.

\section{ONTOLOGY DEVELOPMENT}

Protege 4.2 editor was applied to develop ontology of a subject domain of selecting an educational trajectory; it is a local, freely distributed Java-program. Using this editor, ontologies can be developed, altered, viewed, united, broadened, as well as adjusted to different data formats (text, XML, RDF(S), OWL, etc.). Protege 4.2 has a wide set of operators, based on the logical data model, which allows creating definitions similar to informal descriptions [9, 10]. As a consequence, definitions of complex phenomena can be made with regard to definitions of less complex concepts. Furthermore, a logical model makes it possible to apply reasoning to control mutual coordination of statements and definitions in the ontology, as well as compliance of concepts with the stated definitions [11].

The development of ontology using Protege 4.2 editor was begun with highlighting basic concepts (classes) of a subject domain and relations between them, creation of consistent definitions for basic concepts and defining terms relative to them.

Classes are abstract groups, collections or sets of objects. They can include specimens, other classes, or their combinations. Classes in ontologies are normally organized in a taxonomy; a hierarchical classification of concepts in relation to inclusion. For instance, classes Academic programs and Students and graduates are sub-classes of the class Educational institutions.

Classes (owl:Class) are main components of ontologies, which are described with the help of formal constructions. The developed class hierarchy of the subject domain is given in Fig. 1.

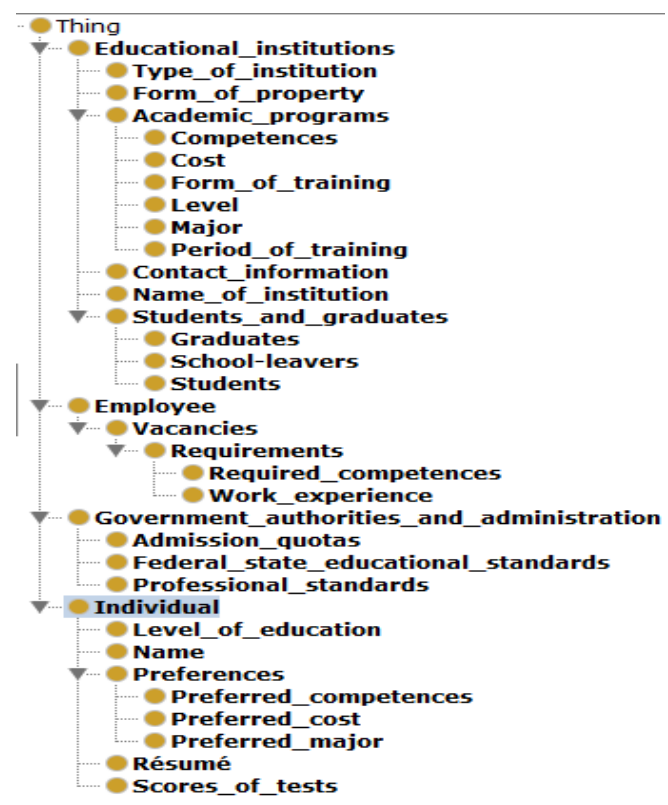

Fig. 1. Class hierarchy of subject domain Selecting an educational trajectory.

Subjects, interested in selecting an educational trajectory and influencing this process, were considered as main classes: 
- Individual (principal subject who makes a decision on selecting an educational trajectory);

- Educational institutions (offer academic programs to implement an educational trajectory);

- Employee (provides information on the demand for competences of any academic program);

- Government authorities and administration (influence the development of academic programs and conditions of their implementation).

Class Individual comprises the following sub-classes:

- Scores of tests, which are restrictions for an educational institution deciding on enrollment of an individual into an academic program;

- Level of education, which an individual has at the moment. This parameter is a restriction when selecting the further step of an educational trajectory.

- Preferences. An individual describes criteria taken into account when selecting an educational trajectory. For instance, a preferable cost of education, major, competences. This list can be extended.

- Résumé is a document containing information on skills, work experience, education etc., required when employing a person.

Class Government authorities and administration consists of the further sub-classes:

- Admission quotas determine priority academic programs with respect to well-trained personnel needed by economy;

- Professional standards feature qualifications required to implement a particular kind of professional activity;

- Federal state educational standards state the rules of implementing an academic program.

The further stage of ontology development is description of properties.

Properties (rdf: Property) in OWL refer to relations between classes or individuals. There are two main types of properties in this language of ontology description:

A Fragment of object properties description is given in Fig. 2 (owl:ObjectProperty).

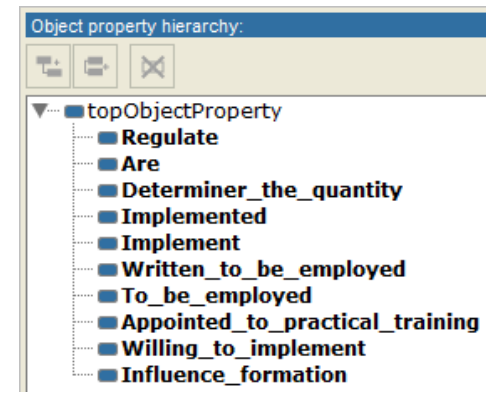

Fig. 2. Object properties of the subject domain.

For instance, the property Appointed to practical training connects the class Students and Vacancies, and Willing to implement - classes School-leavers and Academic programs.

Individuals (specimens of classes or properties) are determined with the help of individual axioms (facts).

Individuals are independent representatives of entities or phenomena, i.d. definite elements of a category. For instance, an individual of the class Major is Applied Information Technology.

A sample axiom is given in Fig. 3. This axiom states two facts simultaneously: an individual of the class "School-leavers" has the name "Ivan I. Ivanov", and is connected through the property Willing to implement with the individual Applied Information Technology stated in the class Major.
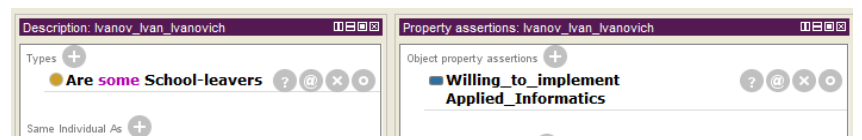

Fig. 3. A sample axiom.

An axiom describing a level of education required from an individual by an employee for a particular vacancy can be considered as a further example.

A semantic network is a network model of a subject domain presented as an oriented graph; its tops (nodes) refer to classes, and arcs (edges) - directed relations or connections linking these nodes. Relation types are shown in the semantic network. A semantic network is shown in Fig. 4, which is developed in ontological modeling a subject domain of selecting an educational trajectory in Protege 4.2 editor $[13,14]$. 


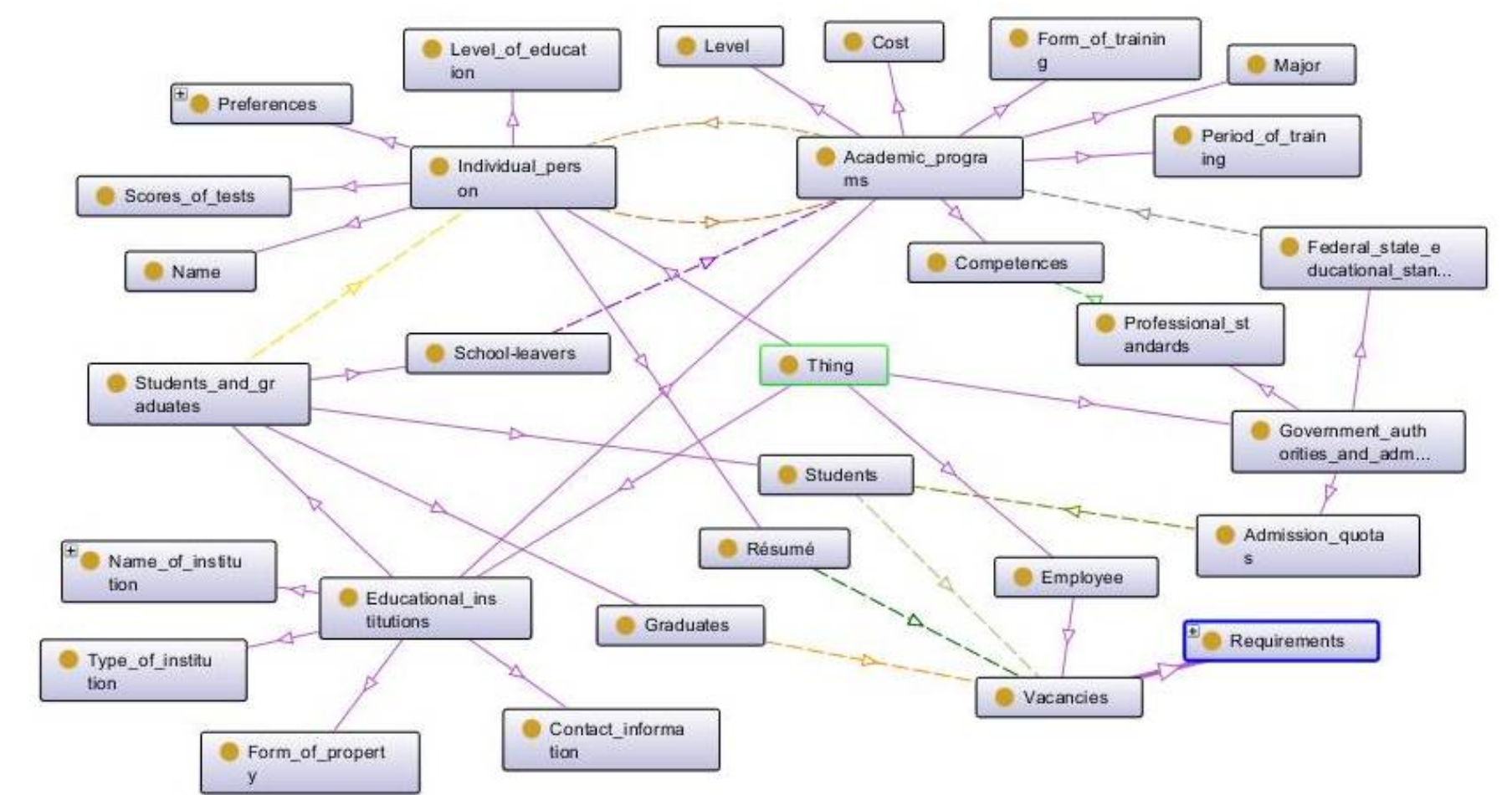

Fig. 4. Semantic network representing relations between subjects

participating in the selection of an educational trajectory

\section{CONCLUSION}

The developed ontology makes it possible to represent all relations between subjects. It helps to make requests for individuals engaged in selecting academic programs with regard to their preferences. Using this ontology, an employee can create requests with a set of required competences and obtain academic programs meeting these requirements. In their turn, educational institutions will be able to monitor vacancies and potential consumers of their services, providing them this way with the most required ones and improving their academic programs. Therefore, the total amount of information joining individuals, employees and educational institutions will be coordinated within this ontology.

\section{ACKNOWLEDGMENTS}

The research is carried out at Tomsk Polytechnic University within the framework of Tomsk Polytechnic University Competitiveness Enhancement Program grant.

\section{REFERENCES}

[1] A. Urintsov, V. Dik, N. Dneprovskaya, "Individual Learning Trajectories as a Key Educational Tool in the Information Society," SMART DIGITAL FUTURES, vol. 262, pp. 652-656

[2] D. Boccanfuso, A. Larouche, M. Trandafir, "Quality of Higher Education and the Labor Market in Developing Countries: Evidence from an Education Reform in Senegal," World development vol. 74, pp. 412-424.
[3] M. Dyrenfurth, M. Murphy, G. Bertoline, "Quality indicators for engineering \& technology education," ASEE Annual Conference and Exposition, Conference Proceedings, 2010, pp. 48

[4] I.Chen, J.Chen, F. Padró, "Critical quality indicators of higher education," Total Quality Management and Business Excellence, 10 June 2015, pp. 17

[5] S. Ivashnova, "The model of projection of a fuzzy individual professional educational trajectory," New Educational Review, vol. 40, Issue 2, pp. 6980, 28 August 2015

[6] G. Barani, F Azma, S. Seyyedrezai, "Quality indicators of hidden curriculum in centers of higher education," Procedia - Social and Behavioral Sciences, vol. 30, pp. 1657-1661, 2011.

[7] Y. Yang, P. Chuang, C. Huang, T. Hou, C Yang. "An efficient adaptive fuzzy learning diagnosis method for e-Learning," Journal of Internet Technology, vol. 16, Issue 3, pp. 391-401, 2015.

[8] Zakharova, A. A.; Lazareva, A. N.; Aleksandrov, A. A. "Mathematical Software For Evaluating And Supporting The Selection Decision On Academic Programs," Proceedings Of The 2016 Conference On Information Technologies In Science, Management, Social Sphere And Medicine (Itsmssm) AcsR-Advances in Comptuer Science Research, vol.: 51, pp.554-559, 2016

[9] Shustova, D.V. Approach to development of semantic fundamentals of information systems for designing and manufacturin aircrafts (In Russian) / D.V. Shustova // Ontology of projecting. 2015, № 1 (15),pp. 70-82.

[10] Nay, F. Ontology Development. A Guide to Creating Your First Ontology / Deborah L. McGuinness - Stanford Knowledge Systems Laboratory Technical Report KSL-01-05 and Stanford Medical Informatics Technical Report SMI-2001-0880, March 2001.

[11] Gruber, T. Toward Principles for the Design of Ontologies Used for Knowledge Sharing // International Journal Human-Computer Studies. 1995, vol. 43, pp. 907-928. 